\title{
Efficient guidelines support professionalism
}

\author{
Line Damsgaard, Anne Grethe Mølbak \\ From Danish Society for Emergency Medicine: Research Symposium 2010 \\ Roskilde, Denmark. 20-21 May 2010
}

\section{Background}

Within the last years departments of emergency medicine have been implemented in Denmark. This process has changed focus on the discipline of acute medicine. Due to the composition of the national postgraduate educational system, our department has a high turnover of young doctors. To avoid oscillations in professional performance of our department, we have to improve, test and implement clinical aids. Efficient guidelines supporting the initial receiving process of patients is one of our intervention strategies. Usually clinical guidelines are based on diagnoses and are focused primarily on an academic description. This study introduces guidelines which are based on immediate symptoms and comprise initial evaluation and treatment along with communication, logistics and flow in order to support the initial clinical performance at the bedside.

\section{Methods}

In context of evidence based evaluation, treatment and communication concerning the emergency patient, and with the clinical symptoms as index, the guidelines are structured using four essential time intervals: The prearrival period, the first 5 minutes, the first 15 minutes and the first hour. For each time interval clinical goals are outlined. Ten scenario simulations are carried out for testing the usability of the specific guideline using young doctors and permanent staff members. Scenarios are rated before and after introduction of the specific guideline using standardized marks for academic, communicative, and logistic skills.

\section{Results}

The clinical performance is improved in all scenarios after implementation of the specific guideline. In the academic level there is an obvious tendency for more than $50 \%$ improvement. Communication within the

\footnotetext{
* Correspondence: agmo@regionsjaelland.dk

Emergency Department, Copenhagen University Hospital in Koege, Denmark
}

team members and the logistic flow are also improved in more than $80 \%$ of the cases. Furthermore the participants' rating of their own performance increases in average from 4 to 8 on visual analogue scales.

\section{Conclusion}

Despite being a small pilot study that can be biased from several factors, it strongly indicates that redesigning clinical guidelines can improve the bedside performance considerably. These results have increased our incentive to continue the creation of symptom specific guidelines. We found a great benefit of testing guidelines in scenario simulations before implementation, and so this will be our future strategy.

Published: 17 September 2010

doi:10.1186/1757-7241-18-S1-P11

Cite this article as: Damsgaard and Mølbak: Efficient guidelines support professionalism. Scandinavian Journal of Trauma, Resuscitation and Emergency Medicine 2010 18(Suppl 1):P11.

\author{
Submit your next manuscript to BioMed Central \\ and take full advantage of: \\ - Convenient online submission \\ - Thorough peer review \\ - No space constraints or color figure charges \\ - Immediate publication on acceptance \\ - Inclusion in PubMed, CAS, Scopus and Google Scholar \\ - Research which is freely available for redistribution \\ Submit your manuscript at \\ www.biomedcentral.com/submit
}

